\title{
Right Atrial Thrombus
}

National Cancer Institute

\section{Source}

National Cancer Institute. Right Atrial Thrombus. NCI Thesaurus. Code C114849.

A blood clot in the right atrium of the heart. 